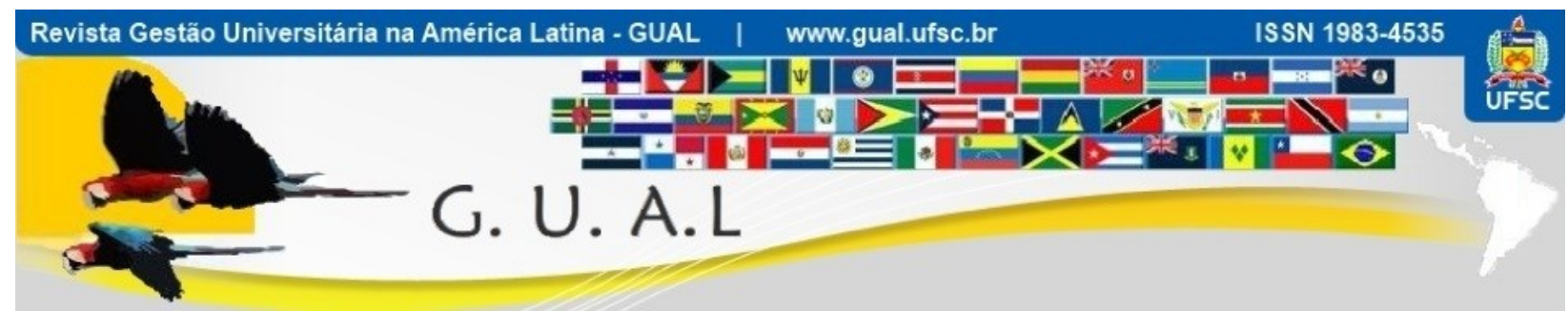

DOI: http://dx.doi.org/10.5007/1983-4535.2017v10n2p171

\title{
SUSTENTABILIDADE NO CURSO DE ADMINISTRAÇÃO: ENSINO É REFLETIDO NO ENADE?
}

\section{SUSTAINABILITY AT BUSINESS MANAGEMENT COURSE: ENADE REFLECTS THIS EDUCATION?}

Fernanda Frankenberger, Doutoranda

Pontifícia Universidade Católica do Paraná - PUC PR ferfrank1@hotmail.com

Janaína Gabrielle Moreira Campos da Cunha Amarante, Doutoranda Pontifícia Universidade Católica do Paraná - PUC PR gabrielle88@hotmail.com

Alboni Marisa Dudeque Pianovski Vieira, Doutora Pontifícia Universidade Católica do Paraná - PUC PR alboni@alboni.com

Recebido em 05/outubro/2015

Aprovado em 08/março/2017

Sistema de Avaliação: Double Blind Review

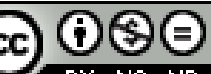

Esta obra está sob uma Licença Creative Commons Atribuição-Uso. 


\title{
RESUMO
}

Após diversas catástrofes ambientais ocorridas pelo mundo e incessantes discussões a respeito do desenvolvimento sustentável necessária, as empresas têm voltado suas preocupações sobre a questão da sustentabilidade e percebido sua importância para um melhor resultado. Neste aspecto, a maneira que a inserção da temática vem sendo realizada na formação de gestores é fator de preocupação no ensino dos cursos de Administração lecionados no Brasil, além de ser exigência do governo Brasileiro, expressa nas Diretrizes Curriculares Nacionais para a Educação Ambiental (Resolução n ${ }^{\circ}$ 02/2012 - CNE/CP), atendendo à demanda da sociedade e do mercado. Assim, as instituições de ensino superior (IES) incorporaram a sustentabilidade no seu Projeto Pedagógico do Curso (PPC) de Administração de forma transversal, como conteúdo de componentes curriculares ou pela combinação deles. Sendo um tema novo no curso, e existindo uma demanda do mercado por gestores capacitados em sustentabilidade, este artigo avaliou, através dos resultados da prova do ENADE de 2012 para o curso de Administração, se os egressos deste curso conheciam os temas referentes à sustentabilidade. A pesquisa, de modalidade comunicação, do tipo descritiva, com caráter bibliográfico e documental, utilizou o levantamento como forma de coleta de dados. Com o emprego da estatística descritiva e aplicação de comparação entre médias, o desempenho das IES foi explorado por diferentes perspectivas, constatando-se que a temática sustentabilidade ainda não está bem consolidada na formação dos futuros administradores, declarando certa fragilidade em relação à compreensão dos alunos a respeito da sinergia entre administração e sustentabilidade. Sugestões para estudos futuros são apontadas de forma a melhorar o resultado encontrado.

Palavras-chave: Sustentabilidade. ENADE. Curso de Administração.

\begin{abstract}
After several worldwide environmental catastrophes and unending discussions about the need of a more sustainable development, many organizations are concerned about sustainability and perceived its importance for a better company performance. In this sense, the way this topic of sustainability is inserted on educational training of new leaders is a preoccupation on teaching process of Business Management courses in Brazil. Besides, Brazilian government enforces this insertion as per the National Curricular Directive for the Environmental Education (Resolution no. 02/2012 - CNE/CP), replying a demand from both society and market / organization. In this way, higher education institutions (HEI) embody sustainability in its Pedagogical Course Project (PPC in Portuguese) of Business Management in a transversal form, as a content component of curriculum or by their combination. As this is a new topic and having a demand from the market for trained leaders in sustainability, this paper evaluated, based on results of ENADE test from 2012 specific for the Business Management Courses, if the students who finished the Course in that year and performed the test knew topics regarding sustainability. This research is performed with communication modality, descriptive type, bibliographic and documental nature, used the collection of secondary data as method for data collection. With the use of descriptive statistics and means comparison, the performance of HEIs was explored by different perspectives, evidencing that sustainability is still not consolidated on future leaders training, showing a certain fragility in relation to the comprehension of students about business and sustainability. Suggestions for future studies are indicated to improve the founded results.
\end{abstract}

Key words: Sustainability. ENADE. Business management course. 


\section{INTRODUÇÃO}

Repetidamente são evidenciadas notícias que revelam a degradação ambiental que a desenfreada necessidade de crescimento econômico das empresas ainda demanda. Tais fatos levam principalmente a sociedade, os políticos, pesquisadores e educadores a acreditar que a sustentabilidade deve ser ensinada aos alunos (CARVALHO, 2011), como forma de educar os egressos das instituições de ensino para serem os líderes do futuro, capazes de modificar esse futuro, seja nos aspectos ambientais, sociais ou econômicos (SHRIBERG, 2000; TAUCHEN e BRANDLI, 2006).

O curso de Administração é o que tem por objetivo formar os futuros administradores, para que liderem e gerenciem as organizações. Neste contexto, as instituições de educação superior (IES) buscam ensinar aos alunos que o verdadeiro administrador é aquele que proporciona o crescimento do lucro da empresa, mantendo a empresa sempre competitiva em um ambiente com rápidas mudanças (CARVALHO, 2011). Voltando-se para as questões inerentes à sustentabilidade, no entanto, para as IES parece ser um desafio muito grande incorporar a sustentabilidade em seus planos de ensino (CARVALHO, 2011).

Tendo em vista esta dificuldade, e paralelamente a isso, percebendo a necessidade tanto do mercado, quanto da sociedade e do meio ambiente de um mundo mais igualitário, resguardando o meio ambiente e mantendo a competitividade e geração de lucro das empresas, o governo federal vem incluindo ao longo de algumas décadas a educação sustentável na agenda da educação no Brasil. Começou com a Constituição Federal de 1988, que no inciso VI do $\S 1^{\circ}$ do artigo 225 determina que o Poder Público deve "promover a Educação Ambiental em todos os níveis de ensino" (BRASIL, 1988, p. 25). Em 1999, a Lei no 9.795, de 27 de abril daquele ano (BRASIL, 1999), regulamentada pelo Decreto $\mathrm{n}^{\circ} 4.281$, de 25 de junho de 2002, instituiu a Política Nacional de Educação Ambiental (PNEA), com o objetivo de estabelecer a educação ambiental em todo território nacional e em todos os níveis de ensino (BRASIL, 2002).

Já em 2012, o Conselho Nacional de Educação, através da Resolução no 2, de 15 de junho, estabeleceu as Diretrizes Curriculares Nacionais para a Educação Ambiental (BRASIL, 2012). Nestas diretrizes estão incluídos os objetivos do ensino superior em educação ambiental, bem como a inclusão dela no Plano de Desenvolvimento Institucional (PDI), que é desdobrado nos Projetos Pedagógicos de Curso (PPC) e no Projeto Pedagógico Institucional (PPI). 
Desta forma, o Plano de Desenvolvimento Institucional (PDI), que "consiste num documento em que se definem a missão da instituição de ensino superior e as estratégias para atingir suas metas e objetivos" (BRASIL, 2015, p. 1), direciona as IES a incorporar os temas que são relevantes para a instituição, seja por força da lei ou orientado pela visão, missão ou valores da instituição. A sustentabilidade começou a ser mencionada nos PDIs como Educação Ambiental e nas versões atuais do PDI a sustentabilidade está incluída com mais detalhamento (PDI UFPR, PDI UTFPR).

Os objetivos das IES indicados no PDI são depois desdobrados para o Projeto Pedagógico de Curso (PPC) (BRASIL, 2012), de tal forma que os cursos ofertados pela IES reflitam em sala de aula a incorporação da sustentabilidade no ensino.

O foco principal de ensino são as disciplinas constantes nas Diretrizes Curriculares, que foram aprovadas para o curso de Administração com o Parecer CNE/CES n 134, de 4 de junho de 2003, que deu origem à Resolução nº 1 , de 2 de fevereiro de 2004 (BRASIL, 2003). Temas como "teorias da administração e das organizações e a administração de recursos humanos, mercado e marketing, materiais, produção e logística, financeira e orçamentária, sistemas de informações, planejamento estratégico e serviços” (BRASIL, 2003, p. 2). Outros temas considerados relevantes para o curso podem ser incluídos de forma transversal e interdisciplinar (BRASIL, 2003).

Com o objetivo de verificar o grau em que o egresso da IES aprendeu os conteúdos ministrados durante o curso, o Exame Nacional de Desempenho de Estudantes (ENADE) foi criado em 2004 (SALUME et al., 2012). Para cada uma das áreas constantes no PPC, existem questões no ENADE que procuram aferir o aprendizado do aluno. No curso de Administração, o ENADE foi realizado nos anos de 2006, 2009 e 2012, e será realizado no fim de 2015. O resultado do exame é uma parte importante para a construção de qualidade do indicador da Educação Superior.

No curso de Administração, a sustentabilidade é um assunto abordado apenas nos últimos anos, não tendo um histórico de ensino sedimentado como estratégia, contabilidade, ou recursos humanos, por exemplo. Assim, torna-se importante avaliar se as IES conseguem educar os alunos para os conceitos referentes à sustentabilidade. A forma de aferição do aprendizado proposto neste artigo é por meio da prova do ENADE. Assim, tem-se como pergunta de pesquisa: Como o ensino da sustentabilidade nas IES do Estado do Paraná é refletido no resultado do ENADE? 
O artigo está estruturado da seguinte forma: na primeira sessão é apresentada a introdução. Na segunda é abordado o referencial teórico e, em seguida, traz-se a metodologia aplicada no estudo. A discussão dos resultados consta da quarta sessão. Por último, as considerações finais.

\section{REFERENCIAL TEÓRICO}

Para a discussão da sustentabilidade nas IES e ENADE, nos tópicos seguintes serão tratados os temas da sustentabilidade no ensino superior e no curso de administração; da sustentabilidade no curso de administração; e do ENADE e da avaliação no Curso de Administração.

\subsection{SUSTENTABILIDADE NO ENSINO SUPERIOR $\quad$ E $\quad$ NO CURSO DE ADMINISTRAÇÃO}

As Instituições de Ensino Superior são um tipo de organização peculiar que, nas últimas décadas, têm sido constantemente demandadas por maior qualidade no ensino, mantendo sua competitividade no mercado. Nos últimos anos, muitas IES surgiram, e elas precisam pensar estrategicamente de forma a garantir sua existência futura. Para isso, necessitam elaborar um planejamento estratégico que esclareça a visão, a missão e a filosofia de trabalho da instituição, que são incluídos no Plano de Desenvolvimento Institucional - PDI (AVILA, 2014), pois as IES possuem a "responsabilidade social no desenvolvimento da sociedade, especialmente na educação de futuros líderes e na proliferação do conhecimento público sobre sustentabilidade" (AMARAL, 2015, p. 156).

A sustentabilidade começa a ter importância no ensino superior a partir de desastres ambientais causados desde a década de 1970, e mais fortemente a partir da Conferência das Nações Unidas realizada no Rio de Janeiro em 1992, onde o MEC (Ministério da Educação e Cultura) organizou um workshop para discutir a educação ambiental no ensino superior. A Carta Brasileira para a Educação, resultado do workshop, recomenda a definição de "metas para a inserção articulada da dimensão ambiental nos currículos, a fim de estabelecer um marco fundamental para implantar a educação ambiental no ensino superior" (BARBIERI, 2004, p. 926). Desta forma, o desenvolvimento sustentável teve uma base, por meio da educação ambiental, para ser promovido nas IES. Conforme ÁVILA (2014, p. 20), “a partir desse momento, no caso da educação brasileira, foi proposta a inserção da sustentabilidade na formação do discente". 
Ganhando força na Conferência das Nações Unidas sobre Desenvolvimento Sustentável (CNDUS), tendo o apoio do Governo Federal e sendo uma demanda de ensino vinda do mercado, diversas leis se seguiram com o foco de vincular a educação ambiental no ensino.

Desde 1965, a educação e o meio ambiente já vinham sendo tratados em Leis, como as 4.771/1965 (BRASIL, 1965) e 5.197/1967 (BRASIL, 1967), mas de forma isolada. Em 1981, com a Lei $n^{0} 6.938$ (BRASIL, 1981), a Política Nacional do Meio Ambiente (PNMA) representou um marco na educação ambiental no Brasil, tendo como um de seus objetivos (artigo $2^{\circ}, X$ ) que a educação ambiental seja amplamente atendida em todos os níveis de ensino (BARBIERI, 2004). Na Constituição Federal de 1988, o desenvolvimento sustentável foi abordado no Capítulo VI, que coloca que a educação ambiental deve ser promovida em todos os níveis de ensino (BARBIERI, 2004, p. 929). A partir de então, ela se torna um dever do Estado.

Apenas com a Lei nº 9.795 de 1999 (BRASIL, 1999), que criou a Política Nacional de Educação Ambiental (PNEA), é que a educação ambiental voltou a ser foco na educação no Brasil, sendo "considerada componente essencial e permanente da educação nacional, devendo ser articulada em todos os níveis e modalidades do processo educativo" (BARBIERI, 2004, p. 930).

Desta forma, o Conselho Nacional de Educação (CNE) estabeleceu, a partir da Resolução n², de 15 de junho de 2012 (BRASIL, 2012), as Diretrizes Curriculares Nacionais para a Educação Ambiental. Ao encontro desta esta decisão, o Plano Nacional de Educação (PNE) para o decênio 2011/2020 estabeleceu pela Lei $\mathrm{n}^{\circ}$ 13.005/2014 que a sustentabilidade socioambiental deveria ser promovida pela IES (BRASIL, 2014). Assim, encontra-se atualmente nas IES a sustentabilidade como parte integrante do ensino.

O Projeto Pedagógico do Curso (PPC) é um documento nas IES que traduz as Diretrizes Curriculares Nacionais em políticas acadêmicas institucionais para os cursos. É a partir dele que as Instituições de Ensino Superior determinam os "conhecimentos e saberes necessários à formação das competências estabelecidas a partir de perfil do egresso; estrutura e conteúdo curricular; ementário, bibliografia básica e complementar; estratégias de ensino; docentes", dentre outros itens (BRASIL, 2015, p. 45). Portanto, a sustentabilidade precisa não só ser incluída nas diretrizes do curso, mas também, e principalmente, ensinada aos alunos. 


\subsection{SUSTENTABILIDADE NO CURSO DE ADMINISTRAÇÃO}

A educação para a sustentabilidade no ensino superior faz-se necessária em todos os cursos, inclusive em decorrência das leis apresentadas anteriormente. Entretanto, na Administração seu ensino é ainda mais relevante por, pelo menos, dois motivos. O primeiro é uma necessidade de o administrador "ter uma boa formação, que permita ampliar sua visão sobre a organização e sobre seu ambiente" (SALUME, 2012, p. 1), haja vista que o administrador é aquele que tomará decisões e definirá os caminhos das organizações. O segundo motivo é em decorrência da utilização, direta ou indireta, por todo e qualquer tipo de organização, pública ou privada, dos recursos naturais, sociais e financeiros disponíveis (BARBIERI, 2004).

No início do ensino da sustentabilidade no curso de Administração, o foco era principalmente econômico (JACOBI et al., 2011). As IES preocupavam-se somente em ensinar ao futuro administrador que ele deveria buscar o lucro para a organização. Mas, com a evolução do estudo da sustentabilidade, que ocorreu principalmente em decorrência dos desastres ambientais, os aspectos sociais e ambientais (além dos econômicos) passaram a ser foco de estudo e de ensino, fortalecido depois da definição do tripé da sustentabilidade (ou TBL - triple bottom line em inglês) por John Elkington em 1997 (ELKINGTON, 2012).

Desta forma, o ensino da sustentabilidade no curso de Administração é de extrema importância, pois o gestor deve conhecer de que forma ele pode contribuir para a sustentabilidade da empresa, tendo em vista os recursos disponíveis e garantindo que as próximas gerações tenham os mesmos recursos a disposição.

\subsection{ENADE E A AVALIAÇÃO NO CURSO DE ADMINISTRAÇÃO}

As organizações, incluindo as IES, estão inseridas em um ambiente em constante evolução. Por isso, é necessário o acompanhamento do desempenho de seus resultados através de indicadores (GOMES et al., 2015), de forma que se tenha maior clareza sobre a situação na qual a organização se encontra. É um indicativo utilizado para mostrar a evolução que se tem em comparação com uma meta definida sobre determinado fator que se mede (BELLEN, 2006; RAMOS e PIRES, 2013). Assim, "o objetivo dos indicadores é agregar e quantificar informações de modo que sua significância fique mais aparente" (BELLEN, 2006, p. 42), podendo ter como resultado final uma mudança na organização, aprendizado ou propaganda (BELLEN, 2006). 
O indicador utilizado para medir o desempenho dos alunos de graduação no Brasil é o Exame Nacional de Desempenho dos Estudantes (ENADE), sendo parte integrante do Sistema Nacional de Avaliação da Educação Superior (SINAES), que foi instituído em 2004 com a Lei no 10.861/2004 (BRASIL, 2004).

A avaliação do ensino superior pelo ENADE, inclui questões de conhecimento geral comuns à todas as áreas de conhecimento e "questões instrumentais que têm a ver tanto com a formação do profissional quanto com a formação do cidadão" (ANDRIOLA, 2009, p. 25). Conforme Aguiar Filho et al. (2013, p. 10), o ENADE possui os seguintes objetivos:

Contribuir para a avaliação dos cursos de graduação por meio da verificação das competências, habilidades e conhecimentos desenvolvidos pelos estudantes;

Aferir o desempenho dos estudantes no que se refere ao uso, síntese e integração de conhecimentos adquiridos ao longo do curso;

Possibilitar aos cursos o acompanhamento dos resultados de suas ações pedagógicas; Avaliar comparativamente a formação oferecida pelas IES aos estudantes das respectivas áreas avaliadas.

Desta forma, as IES "precisam ultrapassar o limite de preocupação de somente ensinar e formar profissionais" (WARKEN, 2014, p. 149), de forma que o resultado do ENADE possa refletir a condição dos estudantes. Além disso, com o resultado do ENADE, pode-se ter uma comparação do aprendizado do alunos entre as diversas áreas do conhecimento de determinado curso, comparando os alunos de todas as instituições de ensino superior.

No curso de Administração, o ENADE foi aplicado nos anos de 2006, 2009 e 2012, e será aplicado novamente ao final de 2015. Na prova de 2006, a sustentabilidade não foi avaliada em nenhuma das questões da prova. Em 2009, ela começou a ser avaliada, ainda que nas questões de formação geral, com foco no consumo consciente. Na prova de 2012, a sustentabilidade também foi foco de questões de formação geral (questão 1), mas foi também incluída em duas questões de conhecimento específico: questões 15 e 31.

\section{PROCEDIMENTOS METODOLÓGICOS}

Ao analisar se o ensino da sustentabilidade nas IES do Estado do Paraná é refletido no resultado do ENADE, este estudo caracteriza-se como teórico-empírico quanto à sua natureza. O enfoque do problema é característico de uma pesquisa descritiva, com caráter bibliográfico e documental, pois tem-se a intenção de descrever de maneira criteriosa os fenômenos que estão passando pelo processo de investigação para viabilizar subsídios ao problema de pesquisa apontado, e "observa, registra, analisa e correlaciona fatos ou fenômenos sem manipulá-los" (CERVO E BERVIAN, 2002, p. 66). Ademais, foi empregado neste estudo o 
método quantitativo de estatística descritiva com o auxílio do software SPSS (Statistical Package for Social Sciences).

A perspectiva temporal aplicada foi cross-section, sendo analisado o ano de 2012 . O ano escolhido justifica-se pelo fato de ser o ano mais recente da prova do ENADE no curso de Administração, além de ter a sustentabilidade como conhecimento específico.

No que tange aos procedimentos de coleta de dados, utilizou-se o de levantamento ao fazer uso de dados secundários. Todos os dados foram coletados no site do ENADE, tendo sido consideradas todas as IES do Estado do Paraná que ofertam o curso de Administração. As notas de todas as questões do curso de Administração foram compiladas, totalizando 21 questões para cada instituição de ensino superior, evidenciando, sobretudo, as duas questões relacionadas à temática "sustentabilidade". No total foram investigadas como amostra deste estudo, 141 Instituições, sendo que dentre elas 102 são de iniciativa privada e 39 são de iniciativa pública.

As Instituições estudadas estão relacionadas na tabela 1, sendo indicada a quantidade de Instituições em cada cidade, totalizando 141 Universidades.

Tabela 1 Instituições do Estado do Paraná com Curso de Administração.

\begin{tabular}{|c|c|c|c|}
\hline Cidade & Quantidade & Cidade & Quantidade \\
\hline AMPERE & 1 & LAPA & 1 \\
\hline APUCARANA & 2 & LARANJEIRAS DO SUL & 1 \\
\hline ARAPONGAS & 1 & LOANDA & 1 \\
\hline ARAUCARIA & 1 & LONDRINA & 8 \\
\hline ASSIS CHATEAUBRIAND & 1 & MANDAGUARI & 1 \\
\hline \multirow[t]{2}{*}{ ASTORGA } & 1 & MANGUEIRINHA & 1 \\
\hline & & MARECHAL & \\
\hline BANDEIRANTES & 1 & RONDON & 3 \\
\hline BARRACAO & 1 & MARINGA & 8 \\
\hline CAFELANDIA & 1 & MATINHOS & 1 \\
\hline CAMBE & 1 & MEDIANEIRA & 1 \\
\hline CAMPINA GRANDE DO SUL & 1 & NOVA ESPERANCA & 1 \\
\hline CAMPO LARGO & 2 & PALMAS & 1 \\
\hline CAMPO MOURAO & 2 & PALOTINA & 1 \\
\hline CAPANEMA & 1 & PARAÍSO DO NORTE & 1 \\
\hline CASCAVEL & 5 & PARANAGUÁ & 2 \\
\hline CASTRO & 1 & PARANAVAI & 2 \\
\hline CLEVELANDIA & 1 & PATO BRANCO & 3 \\
\hline COLOMBO & 1 & PINHAIS & 1 \\
\hline CORNELIO PROCOPIO & 3 & PITANGA & 2 \\
\hline CURITIBA & 26 & PONTA GROSSA & 4 \\
\hline DOIS VIZINHOS & 2 & PORECATU & 1 \\
\hline FOZ DO IGUACU & 7 & REALEZA & 1 \\
\hline \multirow[t]{2}{*}{ FRANCISCO BELTRAO } & 2 & ROLANDIA & 1 \\
\hline & & SANTO ANTONIO & \\
\hline GOIOERE & 1 & PLATINA & 1 \\
\hline GUAIRA & 1 & SAO JOSE DO PINHAIS & 3 \\
\hline GUARAPUAVA & 3 & SAO MATEUS DO SUL & 1 \\
\hline
\end{tabular}


GUARATUBA

IBAITI

IBIPORA

IRATI

IVAIPORA

IVATUBA

JAGUARIAIVA

JANDAIA DO SUL

TOTAL DE UNIVERSIDADES
SAO MIGUEL DO IGUACU

SARANDI

TELEMACO BORBA

TOLEDO

UBIRATA

UMUARAMA

UNIAO DA VITORIA

WENCESLAU BRAZ

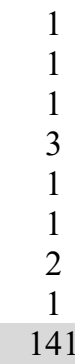

1
1
1
3
1
1
2
1
141

Fonte: Dados organizados pelas autoras, com base no ENADE 2012.

\section{ANÁLISE DOS RESULTADOS}

A partir da análise de 141 Instituições de Ensino Superior do Estado do Paraná, com o intuito de explorar primeiramente a estatística descritiva das questões de sustentabilidade (Questões $n^{\circ} 15$ e $n^{\circ} 31$ ), verificou-se que a média das notas das Instituições da questão $n^{\circ} 15$ foi de 47,14 , indicando um alcance de apenas $47,14 \%$. Este valor não representa uma média ideal, pois está abaixo da metade da pontuação ideal (100). Percebe-se ainda que a nota mínima evidenciada foi 5,10 na Faculdade Paranaense (Iniciativa privada) e a nota máxima foi 73,10 da Universidade Estadual do Oeste do Paraná (Iniciativa pública). O desvio padrão identificado nesta questão foi de 11,68.

\begin{tabular}{|l|r|r|r|r|r|}
\hline & $\mathrm{N}$ & Mínimo & Máximo & Média & Desvio padrão \\
\hline SUST15 & 141 & 5,10 & 73,10 & 47,1404 & 11,68044 \\
N válido (de lista) & 141 & & & & \\
\hline
\end{tabular}

Quadro1 Estatística Descritiva Nota Questão 15 - Sustentabilidade.

Fonte: elaborado pelas autoras.

A segunda questão analisada que trata de sustentabilidade, de $n^{\circ} 31$, resultou em um desempenho inferior à questão 15. A média dos pontos das Instituições foi de 27,24, ficando muito abaixo de uma média ideal. Ademais, percebe-se que a nota mínima entre as Instituições estudadas foi de apenas 8,80, identificada na Faculdade de Ensino Superior de São Miguel do Iguaçu (iniciativa privada). Já a nota máxima da referida questão foi 50,00 , nota está representada pelo Centro Universitário de União da Vitória (iniciativa privada), representando, entretanto, $50 \%$ da nota ideal. O desvio padrão percebido na referida questão foi de 7,98.

\begin{tabular}{|l|r|r|r|r|r|}
\hline & \multicolumn{1}{|c|}{ N } & Mínimo & Máximo & Média & Desvio padrão \\
\hline SUST31 & 141 & 8,80 & 50,00 & 27,2340 & 7,98499 \\
N válido (de lista) & 141 & & & & \\
\hline
\end{tabular}

Quadro 2 Estatística Descritiva nota questão 31 - Sustentabilidade.

Fonte: elaborado pelas autoras. 
Outra análise realizada na presente pesquisa está relacionada à média das notas das duas questões $\left(n^{\circ} 15\right.$ e $\left.\mathrm{n}^{\mathrm{o}} 31\right)$, segregando sobretudo instituições públicas e privadas. Vale ressaltar que este estudo contempla a investigação de 141 Instituições, dentre elas 102 são de iniciativa privada e 39 são de iniciativa pública. No quadro 3 é detalhada a média das notas das duas questões de sustentabilidade avaliadas entre os dois grupos de Instituições:

\begin{tabular}{|ll|r|r|}
\hline Pub/Priv & SUST15 & SUST31 \\
\hline \multirow{3}{*}{ Instituição Pública } & Média & 50,5077 & 28,2154 \\
& $\mathrm{~N}$ & 39 & 39 \\
& Desvio padrão & 11,85319 & 6,99622 \\
\hline \multirow{2}{*}{ Instituição Privada } & Média & 45,8539 & 26,8588 \\
& $\mathrm{~N}$ & 102 & 102 \\
& Desvio padrão & 11,40983 & 8,33370 \\
\hline \multirow{3}{*}{ Total } & Média & 47,1411 & 27,2340 \\
& $\mathrm{~N}$ & 141 & 141 \\
& Desvio padrão & 11,67982 & 7,98499 \\
\hline
\end{tabular}

Quadro 3 Estatística descritiva - Instituições: Pública e Privada. Fonte: elaborado pelas autoras.

Com o auxílio da estatística descritiva, é possível evidenciar que as Instituições públicas apresentam um desempenho superior em relação às Instituições de iniciativa privada. A média das notas das Instituições públicas, no que tange à questão $\mathrm{n}^{\mathrm{o}} 15$ foi de 50,07 , representando um percentual 10,14\% acima da média das notas das Instituições privadas, apontado em 45,85 .

Quanto à questão $\mathrm{n}^{\mathrm{o}} 31$, igualmente relacionada à sustentabilidade, é demonstrado também um melhor desempenho nas Instituições públicas. A média encontrada das notas da Instituições públicas foi de 28,22 , número este que representa um percentual de $5,10 \%$ acima da média das notas das Instituições privadas, que obtiveram a média de apenas 26,85.

Apesar de não ser o mesmo número de Instituições para ambos os grupos, é perceptível a diferença nas notas obtidas entre as Instituições. A partir da análise dos resultados, pressupõe-se que as Instituições públicas trazem, em suas matrizes curriculares do curso de Administração, uma maior ênfase nos assuntos relacionados à gestão sustentável. Entretanto, esta investigação permite também ponderar que ainda se torna necessário, para ambos os grupos, maior foco no ensino quanto à sustentabilidade e à gestão das organizações.

Com o intuito de avaliar o desempenho geral das duas questões sobre sustentabilidade (15 e 31) em relação às demais constantes no teste ENADE 2012, foram consideradas as médias de todas as questões da área da Administração, ilustrado pelo quadro 4. A partir desta 
abordagem, é possível evidenciar que as médias mais altas nas Instituições públicas estão relacionadas em primeiro lugar à questão que envolve o tema de Finanças (Média 53,21), em seguida, a questão de Recursos Humanos assume o segundo lugar entre as melhores médias com 51,77. A questão sobre sustentabilidade $\mathrm{n}^{\mathrm{o}} 15$ aparece na terceira posição, o que representa uma excelente posição dentre às 21 questões analisadas. No quarto lugar do ranking, a logística também se destaca com sua média de pontuação de 50,01. Vale ressaltar que a questão $\mathrm{n}^{\mathrm{o}} 31$ de sustentabilidade não se posicionou com uma evidencia positiva, apresentando-se na $17^{\mathrm{a}}$ colocação.

\begin{tabular}{|c|c|c|c|c|c|c|c|c|c|}
\hline \multirow[b]{2}{*}{ PubPriv } & \multicolumn{3}{|c|}{ Instituição Pública } & \multicolumn{3}{|c|}{ Instituição Privada } & \multicolumn{3}{|c|}{ Total } \\
\hline & Média & N & $\begin{array}{l}\text { Desvio } \\
\text { padrão }\end{array}$ & Média & N & $\begin{array}{l}\text { Desvio } \\
\text { padrão }\end{array}$ & Média & $\mathbf{N}$ & $\begin{array}{l}\text { Desvio } \\
\text { padrão }\end{array}$ \\
\hline QUEST11 - TGA & 23,6564 & 39 & 9,86490 & 20,7735 & 102 & 7,56525 & 21,5709 & 141 & 8,32939 \\
\hline QUEST12 - Finanças & 53,2077 & 39 & 7,77656 & 52,0882 & 102 & 9,70386 & 52,3979 & 141 & 9,19784 \\
\hline QUEST13 - Produção & 34,9949 & 39 & 14,17704 & 28,4265 & 102 & 10,47560 & 30,2433 & 141 & 11,93384 \\
\hline QUEST14 - Logística & 50,0128 & 39 & 10,40314 & 48,2069 & 102 & 9,06441 & 48,7064 & 141 & 9,45029 \\
\hline QUEST15 - Sustentabilid & 50,5077 & 39 & 11,85319 & 45,8539 & 102 & 11,40983 & 47,1411 & 141 & 11,67982 \\
\hline QUEST16 - Estatística & 27,3179 & 39 & 9,14152 & 26,8137 & 102 & 9,11618 & 26,9532 & 141 & 9,09329 \\
\hline QUEST17 - Estatística & 30,4205 & 39 & 8,83731 & 26,4952 & 102 & 8,71755 & 27,5809 & 141 & 8,89542 \\
\hline QUEST18 - RH & 39,7974 & 39 & 12,21977 & 32,3635 & 102 & 11,50406 & 34,4197 & 141 & 12,13027 \\
\hline QUEST19 - Produção & 37,4436 & 39 & 9,86354 & 32,6178 & 102 & 9,08337 & 33,9526 & 141 & 9,51963 \\
\hline QUEST20 - Finanças & 46,9385 & 39 & 8,10239 & 50,0956 & 102 & 9,54762 & 49,2223 & 141 & 9,25153 \\
\hline QUEST21 - Logística & 32,3632 & 38 & 7,50364 & 32,5569 & 102 & 8,46822 & 32,5043 & 140 & 8,19155 \\
\hline QUEST23 - TI & 23,0026 & 39 & 8,36684 & 21,2539 & 102 & 10,59113 & 21,7376 & 141 & 10,02703 \\
\hline QUEST24 - Direito & 35,8821 & 39 & 13,56578 & 33,7598 & 102 & 12,19260 & 34,3468 & 141 & 12,57402 \\
\hline QUEST27 - RH & 24,3923 & 39 & 8,82563 & 19,9000 & 102 & 10,32572 & 21,1426 & 141 & 10,10583 \\
\hline QUEST28 - Empreended| & 38,0013 & 39 & 8,88002 & 36,6020 & 102 & 12,66039 & 36,9890 & 141 & 11,72317 \\
\hline QUEST30 - MKT & 47,7403 & 39 & 11,23912 & 47,1765 & 102 & 11,07321 & 47,3324 & 141 & 11,08192 \\
\hline SUST31 - Sustentabilid & 28,2154 & 39 & 6,99622 & 26,8588 & 102 & 8,33370 & 27,2340 & 141 & 7,98499 \\
\hline QUEST32 - MKT & 31,5128 & 39 & 10,70974 & 28,5029 & 102 & 10,43743 & 29,3355 & 141 & 10,56174 \\
\hline QUEST33 - Estratégia & 42,5949 & 39 & 9,81358 & 40,8618 & 102 & 10,49445 & 41,3411 & 141 & 10,30529 \\
\hline QUEST34 - Estratégia & 29,5872 & 39 & 9,82998 & 27,2451 & 102 & 9,36093 & 27,8929 & 141 & 9,51577 \\
\hline QUEST35 - RH & 51,7769 & 39 & 9,58690 & 49,0608 & 102 & 10,15331 & 49,8121 & 141 & 10,04018 \\
\hline
\end{tabular}

Quadro 4 Estatística descritiva de todas as questões na área de Administração - Enade.

Fonte: elaborado pelas autoras.

Considerando o foco principal deste estudo, que é voltado à sustentabilidade, as Instituições públicas se destacam neste sentido pelo posicionamento em terceiro lugar em uma das questões de sustentabilidade, levando em consideração as médias de todas as questões analisadas. A partir deste achado, identifica-se uma maior preocupação das Instituições públicas do Paraná na abordagem da temática "sustentabilidade" nas matrizes curriculares do curso de Administração. Por outro lado, apesar da sustentabilidade estar presente no curso, 
ainda se torna necessário um maior aprofundamento nesta área, uma vez que a segunda questão ( $\left.n^{0} 31\right)$ não se mostrou relevante em termos de pontuação, fragilizando a afirmação de uma efetiva abordagem aprofundada sobre a temática junto aos acadêmicos de administração.

No que tange às Instituições privadas, na primeira posição das médias das notas de todas as questões do ENADE, assim como nas Instituições públicas, a área de finanças assume a liderança com as duas questões mais pontuadas, com média 52,09 e 50,09. Em segundo lugar, a área de Recursos Humanos surpreende também com a média de 49,06 e, em terceiro lugar, a logística pontua com a média de 48,21. Na quarta posição, a área de Marketing apresenta a média de 47,17 . Representada pela questão $\mathrm{n}^{\circ} 15$, a sustentabilidade emerge na $5^{\mathrm{a}}$ posição do ranking, com a média de 45,85 . Todavia, ao apontar a questão $\mathrm{n}^{\circ} 31$ de sustentabilidade, o posicionamento é consideravelmente rebaixado para a $16^{\mathrm{a}}$ posição.

Deste modo, assim como nas Instituições públicas, por mais que exista a abordagem a respeito da sustentabilidade, ainda se percebe grande deficiência de compreensão, a qual pode ser refletida na média da pontuação das Instituições privadas.

Os gráficos 1 e 2, adiante, ilustram o desempenho das IES de forma separada, frente a todas as questões aplicadas e válidas no ENADE 2012:

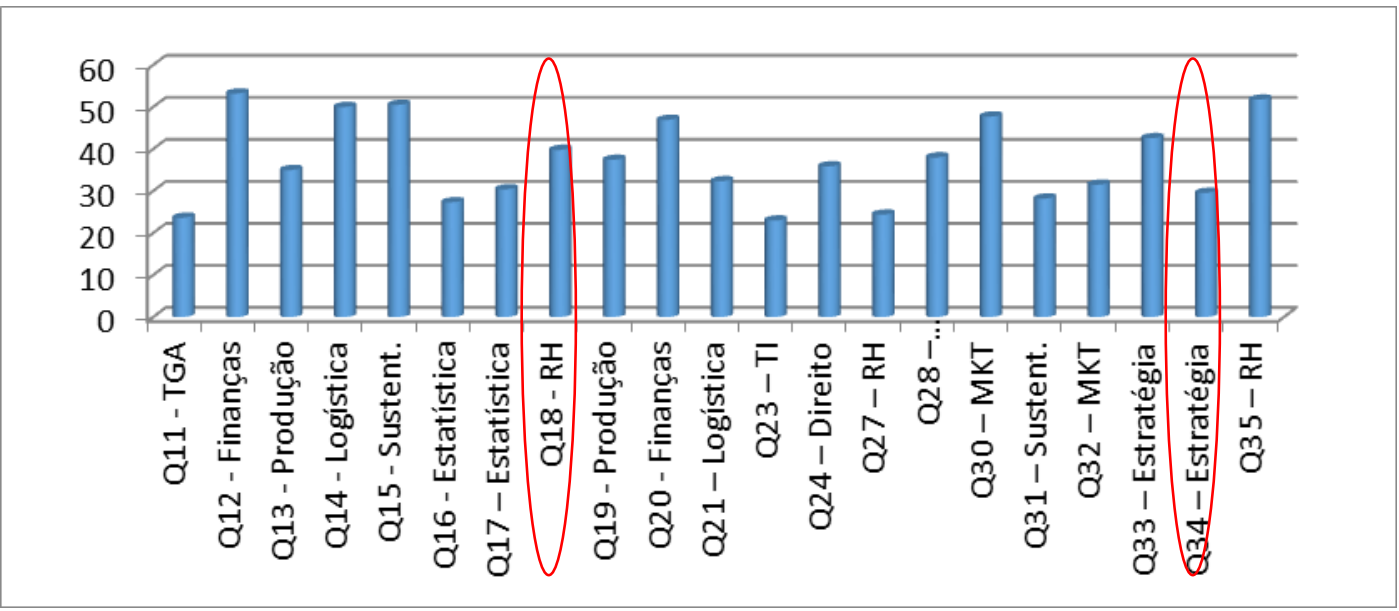

Gráfico 1 Desempenho médio das Instituições públicas nas disciplinas de Administração.

Fonte: elaborado pelas autoras. 


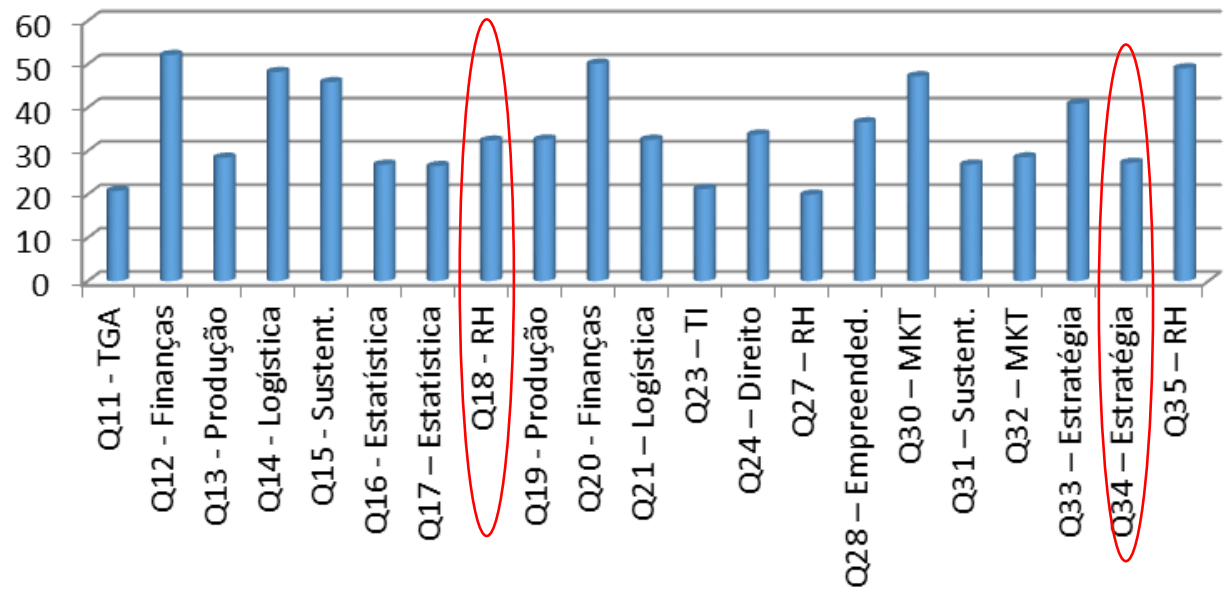

Gráfico 2 Desempenho médio das Instituições privadas nas disciplinas de Administração. Fonte: elaborado pelas autoras.

A última análise deste estudo, apresentada no gráfico 3, abaixo, voltou-se para a média geral, considerando ambos os grupos de Instituições, de modo que o posicionamento da média da questão $n^{0} 15$ foi a $6^{a}$ colocação (Média 47,14) e o da questão $n^{0} 31$ o na $17^{a}$ colocação (Média 27,23). Assim, a partir dos achados deste estudo, constata-se que a temática sustentabilidade ainda não está bem consolidada na formação dos futuros administradores, apresentando certa fragilidade na efetiva compreensão dos alunos a respeito das abordagens inerentes à área.

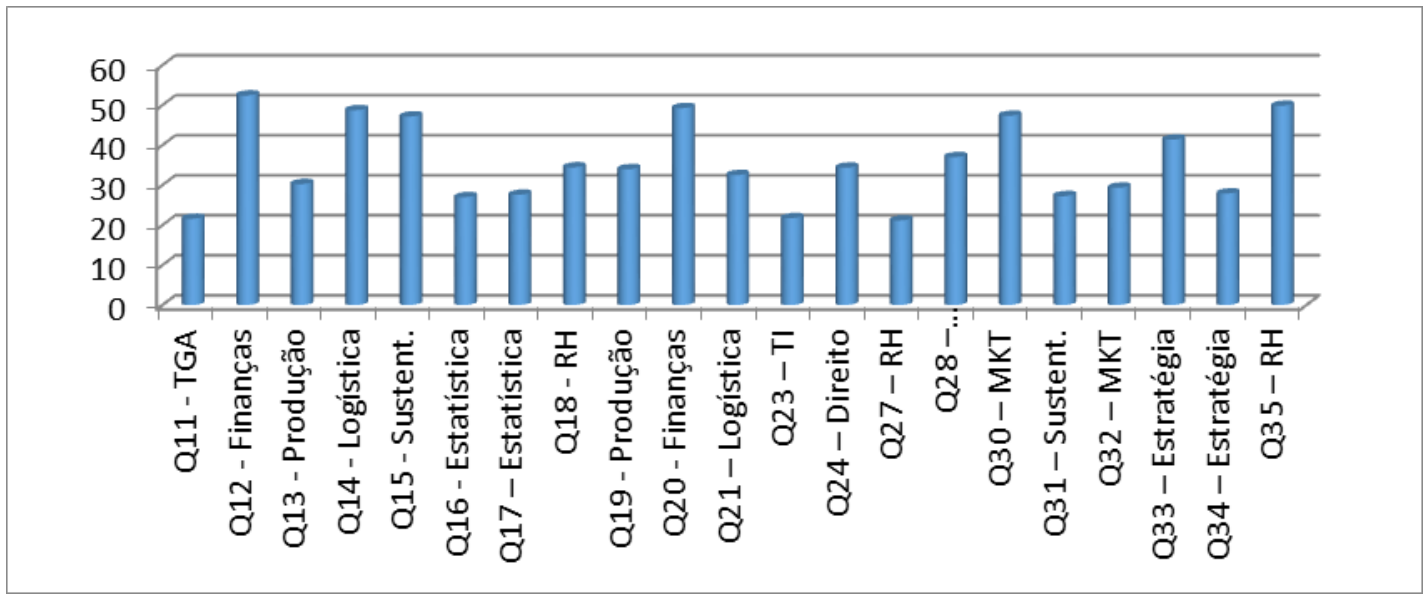

Gráfico 3 Desempenho médio das IES em todas as disciplinas de Administração. Fonte: elaborado pelas autoras.

\section{CONCLUSÃO}

As evidências coletadas na presente pesquisa contribuem para aumentar a compreensão da importância do aprofundamento do conhecimento da sustentabilidade no 
curso de administração das Instituições de Ensino Superior (IES), sejam elas públicas ou privadas. Utilizando o contexto das IES do Estado do Paraná como suporte de investigação, os esforços empregados neste estudo buscaram analisar como o ensino da sustentabilidade nas IES do Estado do Paraná é refletido no resultado do ENADE.

Neste contexto, foram coletadas as notas de todas das questões do ENADE 2012, de 141 IES, questões estas voltadas ao campo da administração, com um foco específico e principal em duas questões focadas na sustentabilidade. A principal característica destas questões é o embasamento na relação entre a administração empresarial e a gestão sustentável.

Com o emprego da estatística descritiva e aplicação de comparação entre médias, o desempenho das IES foi explorado por diferentes perspectivas. Por meio da busca da média das IES, inicialmente identificou-se que, apesar de não apresentar uma média ideal, as IES obtiveram um melhor desempenho na questão $n^{\circ} 15$, todavia, o desempenho da questão $n^{\circ} 31$ ficou muito abaixo. A segunda etapa da análise voltou-se para verificar o desempenho das médias das IES públicas e privadas, de maneira segregada, obtendo melhor destaque as Instituições públicas, sendo, porém, limitação do estudo a característica da amostra, pelo fato de ser menor o número de IES públicas.

Outra evidência do presente estudo está na averiguação do posicionamento das médias das pontuações das questões de sustentabilidade em relação às demais abordadas no ENADE 2012, não apresentando um real nivelamento das médias das questões de sustentabilidade, apresentando-se como um fator preocupante.

Os achados deste estudo revelam que ainda a temática "sustentabilidade" não está bem consolidada na formação dos futuros administradores, declarando certa fragilidade em relação à compreensão dos alunos a respeito da sinergia entre administração e sustentabilidade. Esta afirmação é validada pela análise do desempenho das notas obtidas nas questões analisadas, de modo que não se percebe uma linearidade na representação entre ambas, tanto na análise de média entre elas (questões de sustentabilidade) como também entre as demais questões das disciplinas de administração.

A abordagem realizada por esta pesquisa pode ser considerada a primeira no âmbito nacional, e assim como outros estudos, não esgota ou encerra o assunto. Muito pelo contrário, é um ingresso para o aprofundamento da questão. Neste sentido, sugere-se que pesquisas futuras trabalhem com a investigação dos PDI's e documentos pedagógicos que retratem a realidade das IES em sua matriz curricular a respeito da sustentabilidade, buscando confrontar 
os resultados no ENADE em relação ao efetivo envolvimento e comprometimento das Instituições na formação de administradores que gerenciem seus futuros negócios com responsabilidade sustentável.

\section{REFERÊNCIAS}

AGUIAR FILHO, A.S.; BATISTA, M.E.; HICKSON, R.S. Implementação de ações voltadas ao ENADE a partir dos resultados da auto avaliação institucional: um estudo de caso. XIII Colóquio Internacional sobre Gestão Universitária nas Américas. 2013-11-27.

AMARAL, L. P; MARTINS, N.; GOUVEIA, J.B. Quest for a sustainable university: a review. International Journal of Sustainability in Higher Education, v. 16, n. 2, p. 155 $172,2015$.

ANDRIOLA, W.B. Fatores Institucionais Associados aos Resultados do Exame Nacional de Desempenho Estudantil (ENADE): um estudo dos cursos de graduação da Universidade Federal do Ceará (UFC). REICE. Revista Iberoamericana sobre Calidad, Eficacia y Cambio en Educación, 2009, v. 7, n. 1, p. 22-49.

ÁVILA, L.V. A perspectiva da sustentabilidade no plano de desenvolvimento institucional: um estudo das instituições federais de ensino superior. 2014. 117 f. Dissertação (Mestrado). Universidade Federal de Santa Maria.

BARBIERI, J.C. A educação ambiental e a gestão ambiental em cursos de graduação em administração: objetivos, desafios e propostas. RAP, 2004, v. 36, n. 6, p. 919-946.

BELLEN, H. M. van. Indicadores de sustentabilidade: uma análise comparativa. 2. ed. Rio de Janeiro: Editora FGV, 2006.

BRASIL, Lei $\mathrm{n}^{\circ}$ 4.771, de 15 de setembro de 1965. Institui o novo Código Florestal. Disponível em: $<$ http://www.planalto.gov.br/ccivil_03/Leis/L4771.htm>. Acesso em: 07 jul 2015.

BRASIL, Lei n ${ }^{\circ}$ 5.197, de 3 de janeiro de 1967. Dispõe sobre a proteção à fauna e dá outras providências. Disponível em: <http://www.planalto.gov.br/ccivil_03/Leis/L5197.htm>. Acesso em: 07 jul 2015.

BRASIL, Lei nº 6.938, de 31 de agosto de 1981. Dispõe sobre a Política Nacional do Meio Ambiente, seus fins e mecanismos de formulação e aplicação, e dá outras providências. Disponível em: < http://www.planalto.gov.br/ccivil_03/Leis/L6938.htm>. Acesso em: 07 jul 2015.

BRASIL, Constituição (1988). Constituição da República Federativa do Brasil. Diário Oficial [da República Federativa do Brasil], Brasília, DF, n. 191-A, p. 1-32, 5 out. 1998. Disponível em:

$<$ http://www.planalto.gov.br/ccivil_03/Constituicao/DOUconstituicao88.pdf $>$. Acesso em: 05.07.2015. 
BRASIL, Lei n ${ }^{\circ}$ 9.795, de 27 de abril de 1999. Dispõe sobre a educação ambiental, institui a Política Nacional de Educação Ambiental e dá outras providências. Disponível em: $<$ http://www.planalto.gov.br/ccivil_03/leis/19795.htm>. Acesso em: 05 jul 2015.

BRASIL, Decreto $n^{\circ} 4.281$, de 25 de junho de 2002. Regulamenta a Lei $n^{\circ} 9.795$, de 27 de abril de 1999, que institui a Política Nacional de Educação Ambiental, e dá outras providências. Disponível em: < http://www2.camara.leg.br/legin/fed/decret/2002/decreto4281-25-junho-2002-459149-publicacaooriginal-1-pe.html>. Acesso em: 05 jul 2015.

BRASIL, Parecer CNE/CES n ${ }^{\circ} 134$, de 4 de junho de 2003. Diretrizes Curriculares Nacionais do curso de graduação em Administração. Disponível em:

$<$ http://portal.mec.gov.br/cne/arquivos/pdf/ces-0134.pdf>. Acesso em: 06 jul 2015.

BRASIL, Resolução ${ }^{\circ}{ }^{1}$, de 2 de fevereiro de 2004. Institui as Diretrizes Curriculares Nacionais do Curso de Graduação em Administração, Bacharelado, e dá outras providências. Disponível em: $<$ http://portal.mec.gov.br/cne/arquivos/pdf/rces01_04.pdf $>$. Acesso em: 06 jul 2015.

BRASIL, Lei no 10.861, de 14 de abril de 2004. Institui o Sistema Nacional de Avaliação da Educação Superior - SINAES - e dá outras providências. Diário Oficial [da República Federativa do Brasil], Brasília, DF, n. 72, p.3-4, 13 jul. 2015.

BRASIL. Plano Nacional de Educação - PNE. Por um plano nacional de educação (20112020) como Política de estado. Anped. Rio de Janeiro, 2011.

BRASIL, Resolução n ${ }^{\circ}$ 02/2012 - CNE/CP, de 15 de junho de 2012. Estabelece as Diretrizes Curriculares Nacionais para a Educação Ambiental. Diário Oficial [da República Federativa do Brasil], Brasília, DF, n. 116, p.70-71, 18 jun. 2012.

BRASIL, Lei $n^{\circ} 13.005$, de 25 de junho de 2014. Aprova o Plano Nacional de Educação PNE e dá outras providências. Disponível em:

$<$ http://www.planalto.gov.br/ccivil_03/_ato2011-2014/2014/1ei/113005.htm>. Acesso em: 06 jul 2015.

BRASIL, Instrumento de Avaliação de Cursos de Graduação presencial e a distância.

Disponível em:

$<$ http://download.inep.gov.br/educacao_superior/avaliacao_cursos_graduacao/instrumentos/2 012/instrumento_com_alteracoes_maio_12.pdf>. Acesso em: 13 jul 2015.

BRASIL. Formulário do Plano de Desenvolvimento Institucional - PDI. Disponível em: $<$ http://www2.mec.gov.br/sapiens/Form_PDI.htm> Acesso em: 05 jul 2015.

CARVALHO, S.L.G. Educação para a sustentabilidade em escolas de administração de empresas: a perspectiva de coordenadores acadêmicos no Brasil. 2011. 157 f. Dissertação (Mestrado). Universidade Presbiteriana Mackenzie de São Paulo.

CERVO, A. L.; BERVIAN, P. A. Metodologia científica. 5. ed. São Paulo: Prentice Hall, 2002. 
ELKINGTON, J. Sustentabilidade: canibais com garfo e faca. São Paulo: M. Books do Brasil Editora Ltda, 2012.

GOMES, C.M.; KNEIPP, J.M.; KRUGLIANSKAS, I.; BARBIERI DA ROSA, L. A.; BICHUETI, R.S. Management for Sustainability: An analysis of the key practices according to the business size. Ecological Indicators. v. 52, p. 116-127, 2015.

JACOBI, P.R.; RAUFFLET, E.; ARRUDA, M.P. Educação para a sustentabilidade nos cursos de administração: reflexão sobre paradigmas e práticas. Revista de Adminstração Mackenzie, v. 12, n. 3, p. 21-50, 2011.

UNIVERSIDADE FEDERAL DO PARANÁ. Plano de Desenvolvimento Institucional 2012-2016. Resolução $n^{\circ} 15 / 12-C O U N$ - Disponível em:

<www.ufpr.br/soc/descarregar_arquivo.php?cod=703>. Acesso em: 06 jul 2015.

UNIVERSIDADE TECNOLÓGICA FEDERAL DO PARANÁ. Plano de Desenvolvimento Institucional 2013-2017. Disponível em: $<$ http://www.utfpr.edu.br/a-instituicao/documentosinstitucionais/pdi-2013-2017/plano-de-desenvolvimento-institucional-2013-2017/view $>$.

Acesso em: 06 jul. 2015.

RAMOS, T.; PIRES, S.M. Sustainability Assessment: The Role of Indicators. IN:

Sustainability Assessment Tools in Higher Education Institutions: Mapping Trends and Good Practices Around the World. Switzerland. Springer International Publishing. 2013.

SALUME, P.K.; BRAGA, J.O.; LATINI, F.H.; CHEQUER, K.M.; GONÇALVES, R.F.; RIBEIRO, D. Q. O ENADE avalia o administrador de acordo com o perfil exigido pelo MEC? Uma análise sob a perspectiva da taxonomia de Bloom. IN: XXXVI Encontro ANPAD. 36., 2012, Rio de Janeiro.

SHRIBERG, M. Sustainability management in campus housing: A case study at the University of Michigan. International Journal of Sustainability in Higher Education, v. 1, n. 2, p. 137-153, 2000.

TAUCHEN, J.; BRANDLI, L.L. A Gestão Ambiental em Instituições de Ensino Superior: um modelo para implantação em campus universitário. Gestão e Produção, v. 13, n. 3. p. 503$515,2006$.

WARKEN, I.L.M.; HENN, V.J.; ROSA, F.S. Gestão da Sustentabilidade: um estudo sobre o nível de sustentabilidade socioambiental de uma instituição federal de ensino superior.

Revista de Gestão, Finanças e Contabilidade, v. 4, n. 3, p. 147-166, 2014. 